\title{
Análise do impacto no lucro líquido financeiro nas empresas de capital aberto listadas na BOVESPA que compõem o IBOVESPA após a adoção das IFRS
}

\section{ARTIGO ORIGINAL}

DANTAS, Luiz Antônio de Oliveira [1], OLIVEIRA, Fernando Grecco de [2], GARCIA, Bruno Henrique Cisotto [3]

DANTAS, Luiz Antônio de Oliveira; OLIVEIRA, Fernando Grecco de; GARCIA, Bruno Henrique Cisotto. Análise do impacto no Lucro Líquido financeiro nas empresas de capital aberto listadas na BOVESPA que compõem a IBOVESPA após a adoção das IFRS. Revista Científica Multidisciplinar Núcleo do Conhecimento. Vol 03. Ano 01, Ed. 05, pp. 11-26. Maio 2016. ISSN: 2448-0959

\section{RESUMO}

$\mathrm{O}$ artigo teve como objetivo analisar o impacto ocorrido no lucro líquido das empresas de capital aberto listadas na BM\&FBOVESPA que compõem o IBOVESPA após a adoção das normas internacionais de contabilidade adotadas no Brasil com a introdução da Lei 11.638/07 e posterior aprovação dos pronunciamentos contábeis. Para tanto, realizou-se uma extensa revisão da literatura para proporcionar fundamentos teóricos. Aplicou-se para realização da pesquisa o teste de diferença das médias com nível de significância de $5 \%$ e $1 \%$. Os dados para a realização da pesquisa foram extraídos do software Economática ${ }^{\circledR}$ após o prazo para divulgação das DFPs (Demonstrações Financeiras Padronizadas) estabelecido pela CVM (Comissão de Valores Mobiliários). Os resultados evidenciaram que houve uma diferença significativa no lucro líquido financeiro das empresas de capital aberto que compõem o IBOVESPA após a adoção das normas internacionais de contabilidade para $41 \%$ das empresas analisadas a um nível de significância de 5\% e uma diferença significativa para 32\% das empresas para um nível de significância de $1 \%$.

Palavras-chaves: Lucro líquido, empresas de capital aberto, adoção das normas internacionais de contabilidade, IFRS.

\section{INTRODUÇÃO}


Atualmente, existe um grande número de empresas com suas ações negociadas na BM\&F BOVESPA (Bolsa de Valores, Mercadorias e Futuros de São Paulo). As empresas listadas na bolsa apresentam-se como pertencentes a diversos ramos e segmentos, deixando em evidência a diversidade presente. As vantagens adquiridas pelas empresas que decidem participar desse tipo de processo, a saber, a negociação de suas ações em bolsa de valores, pode ser resumida na seguinte afirmação: " empresas utilizam a Bolsa para captar recursos e financiar seus projetos de crescimento visando tornarem-se mais competitivas." (BOVESPA, 2014, p. 1). Desse modo, percebe-se a necessidade de se compreender a complexidade que envolve tais relações comerciais, o que será feito no texto em questão a partir da análise do impacto no lucro líquido ocorrido nas empresas de capital aberto após a adoção das normas internacionais de contabilidade.

A adoção das novas normas de contabilidade, com a introdução da Lei 11.638/07 e posterior aprovação dos pronunciamentos contábeis CPC, trouxe um novo tempo para a contabilidade das empresas brasileiras. Não houve uma simples mudança de normas. A internacionalização trouxe uma mudança de filosofia, postura e pensamento, destacando-se três tópicos: Essência sobre a forma, primazia da análise de riscos e benefícios sobre a propriedade jurídica e normas orientadas por princípios. Esse novo cenário passou a exigir dos profissionais contábeis envolvidos nas demonstrações financeiras uma maior subjetividade, pois a nova norma é baseada em princípios e, desse modo, muitos assuntos passaram a exigir maiores julgamentos profissionais (MARTINS e SANTOS, 2008; SANTOS e CALIXTO, 2010).

Se por um lado a adoção das novas práticas contábeis trouxe uma série de benefícios no tocante à transparência e à qualidade da informação apresentada, por outro lado surgiram "potenciais instrumentos de manipulação." (BAPTISTA 2009). Diante desse novo cenário, o lucro líquido contábil passou a sofrer muitas interferências dos novos padrões contábeis. Desse novo cenário, surge o problema da pesquisa: até que ponto a adoção das normas internacionais de contabilidade impactou o lucro líquido contábil das empresas de capital aberto listadas na BOVESPA?

Esta pesquisa tem como objetivo analisar as empresas de capital aberto listadas na BM\&F Bovespa que compõem o IBOVESPA após a adoção das IFRS (International Financial Reporting Standards) no que diz respeito ao impacto no lucro líquido financeiro. Para tanto, a fim de que a questão apresentada seja elucidada em todos os seus aspectos, o caminho percorrido para a análise foi feito a partir da especificidade de cada conceito e da relevância de cada um deles para o tema em questão, apresentação da metodologia empregada para a análise de dados, análise estatística do lucro líquido após a introdução das IFRS comparativamente com um período anterior a adoção das normas internacionais e conclusão.

A justificativa para realização desse trabalho é a contribuição que ele poderá gerar para um melhor entendimento do possível impacto da adoção das normas internacionais de contabilidade como determinante do lucro líquido financeiro das empresas de capital aberto. Não se pretende com esse artigo abordar todos os cenários que possam ter alterado de alguma forma a expectativa de lucro líquido das empresas analisadas, pois o lucro líquido é impactado por diversos fatores não contábeis, como a taxa de juros da economia, o cenário político, taxa de reinvestimento entre outros tantos.

\section{MUDANÇAS CONTÁBEIS}

Braga et al. (2011) analisam as mudanças das práticas contábeis que foram adotadas no Brasil através do 
marco regulatório da contabilidade financeira, mediante a promulgação da Lei 11.638/07 e a MP 449/08. Com relação à primeira, criada para convergir os padrões contábeis locais para internacionais, o autor em questão atribui como consequências uma série de modificações na legislação no que se refere às práticas contábeis no Brasil, sendo a principal razão de tais consequências justamente a convergência acima citada, isto é, de padrões contábeis locais para internacionais. Em outras palavras, após a lei em questão, o "precedente legal necessário para a consecução dessa convergência dos padrões contábeis foi estabelecido".

Considerando as grandes alterações trazidas pela lei, LODDI (2014) afirma que modificações na legislação societária há muito tempo vinham sendo solicitadas pelas empresas brasileiras, mas que após sua criação, poucas se apresentaram como preparadas para as alterações, isto é, algumas transformações são limitadas e podem realizar-se somente sob o auxílio da lei, mas com relação àquelas que não o são, as mesmas não foram demonstradas, mesmo que minimamente, pelas empresas que solicitavam mudanças.

É importante que seja citada a Lei 6.404, de 1976, uma vez que a Lei 11.638 de 2007 foi elaborada a partir de modificações em relação à mesma. De modo geral, apesar de existirem críticas sobre os padrões internacionais no que se refere à contabilidade, a ideia de se adotar os padrões em questão diz respeito ao objetivo de alinhar a contabilidade relacionada às empresas brasileiras com as normas do mundo como um todo, caracterizado pelo forte aspecto da globalização.

Santos e Calixto (2010) comentam sobre a harmonização contábil entre o padrão das normas contábeis nacionais com o IFRS, para que o Brasil se alinhasse à internacionalização de sua contabilidade, apontando que a essência sobre a forma e a transparência para o investidor representaria profunda transformação na contabilidade, no mercado profissional e no currículo disciplinar da área.

No Brasil, a expectativa da convergência com o IFRS era de que, como ocorreu em outros países, as empresas adquirissem benefícios de liquidez, menores custos de capital e maior valorização e atratividade no mercado. Para Santos e Calixto (2008), as principais mudanças introduzidas pela Lei 11.368/07 e pela MP 449/08 foram: nos instrumentos financeiros; nas operações de arrecadamento mercantil; no ativo intangível e ativo diferido; na redução de ativos ao valor recuperável; no ajuste a valor presente; na equivalência patrimonial; nos custos de transação e prêmios na emissão de títulos; nas subvenções e assistências governamentais; na reavaliação de ativos; no pagamento baseado em ações.

De maneira a analisar quais foram os impactos da adesão à nova lei no Lucro Líquido (LL) e Patrimônio Líquido (PL) das empresas, Santos e Calixto (2010) colheram as demonstrações financeiras padronizadas (DFPs) de 2008, fornecidas pelas empresas listadas na Bovespa - dos segmentos nível 1, 2 e novo mercado - através do sistema da CVM até 10 dias depois do encerramento do prazo regulamentar (10 de abril de 2009). Da amostra analisada, foram excluídas as instituições financeiras, as empresas com data de encerramento diferentes de 31/12 e aquelas que não forneceram DFPs nos dois anos de análise dos autores.

De acordo com Santos e Calixto (2010), das 318 empresas observadas, apenas $28 \%$ reapresentaram as demonstrações contábeis de 2007 conforme as regras de 2008 (para fins de comparação), e apenas $11 \%$ apresentaram em NE a reconciliação do efeito da Lei 11.638/07 no resultado e PL dos dois anos analisados. Os autores dispõem que as empresas não privilegiaram a transparência, pois, das que declararam efeito da nova lei, apenas $41 \%$ reapresentaram os balanços de 2007 e apenas $18 \%$ publicaram 
a tabela de reconciliação dos dois anos - o que dificulta o trabalho dos analistas, ao causar certa "confusão contábil" e prejudicar a análise dos balanços de 2008.

Santos e Calixto (2010) reportam uma inconsistência no efeito da nova lei contábil sobre os resultados reportados pelas empresas em 2007 e 2008: pois dentre as 175 empresas que publicaram a tabela de conciliação dos resultados de 2007 e/ou 2008, observou-se um aumento médio de 8,1\% no resultado de 2007 e uma diminuição média de $-7 \%$ em 2008. A amostra foi reduzida para 34 empresas que ofereceram a tabela de reconciliação de ambos os anos analisados, permitindo que os autores constatassem que essas inconsistências se relacionavam aos impactos da crise financeira global. Em razão das dificuldades, os autores recomendam maiores investimentos na transparência, por parte das organizações e seus investidores, principalmente no período de transição até o full IFRS em 2010.

Braga et al. (2011) realizaram uma pesquisa sobre as mudanças trazidas pela Lei n. ${ }^{\circ}$ 11.638/07, a MP 449/08 e os Pronunciamentos emitidos pelo Comitê de Pronunciamentos Contábeis (CPC) em relação às práticas contábeis adotadas no Brasil, com a vigência a partir de 2008. De acordo com os autores, tais mudanças foram executadas para converter o padrão contábil local para o internacional, estabelecendo um precedente legal. Por exemplo, a Lei n. ${ }^{\circ}$ 11.638/07 altera a Lei n. ${ }^{\circ}$ 6.385/76 (Lei da Comissão de Valores Mobiliários), lançando a possibilidade da CVM, Banco Central do Brasil e outros órgãos reguladores de celebrarem convênio com entidade que vise estudar ou divulgar os princípios, normas e padrões de contabilidade e de auditoria.

Em uma pesquisa com 75 empresas de capital aberto que negociam as ações na Bovespa, em diversos setores da economia (exceto financeiras, seguradoras e holdings), Braga et al. (2011) analisam as estatísticas dos indicadores econômico-financeiros calculados com base nas demonstrações contábeis do exercício de 2007, publicados em 2008 em comparação com a reapresentação dos dados em 2009.

Ao utilizarem o teste não-paramétrico de Wilcoxon, os autores afirmam que, a um nível de significância de 0,05, a média dos índices de endividamento oriundos das demonstrações contábeis de 2007 "originais" para a amostra de 75 empresas é significativamente diferente da média dos índices de endividamento oriundos das demonstrações "reapresentadas" das mesmas empresas, quando sob os termos previstos pela Lei n. ${ }^{\circ} 11.638 / 07$. De acordo com o teste, percebeu-se um número significativamente maior de empresas que aumentaram o índice de endividamento em comparação àquelas que tiveram esse índice reduzido. Presumiu-se que esse efeito seria derivado das alterações que afetaram o patrimônio líquido, causados pelas mudanças na mensuração de instrumentos financeiros, na avaliação de investimentos societários, não reconhecimento dos itens do ativo diferido, por exemplo.

Determinou-se como efeito das alterações da Lei n. ${ }^{\circ}$ 11.638/07: redução do componente patrimônio líquido (39 dos 44 casos houve aumento do endividamento); aumento do passivo exigível (em 26 dos 44 casos); ambos os fatores, simultaneamente (22 dos 44 casos). Em relação ao índice de rentabilidade, houve o mesmo valor antes e depois em 12 empresas, já em 26 ocorreu sua redução e em 37 houve o aumento, mas sem amplitude suficiente para alteração da média do antes e depois. Situação semelhante se passou quanto ao índice de composição do endividamento, o índice de imobilização dos recursos não correntes e o índice de participação do resultado nas despesas operacionais.

\section{MUDANÇAS RELACIONADAS}




\section{INTERNACIONALIZAÇÃO}

Considerando a importância da internacionalização e suas normas, conforme citado no tópico anterior, é válido abordar três fatores considerados consequências das transformações trazidas por estas normas, sendo eles: a chamada "essência sobre a forma", em primeiro lugar; a primazia da análise de riscos e benefícios sobre a propriedade jurídica, em segundo e, por fim, as chamadas "normas orientadas por princípios".

Com relação ao primeiro deles, isto é, a essência sobre a forma, é preciso ressaltar, de início, que as normas relacionadas à internacionalização foram pensadas a partir do fato de que durante muito tempo não houve um padrão que unificasse todos os países. O motivo de tal complexidade em relação à contabilidade se deve ao consenso por parte dos estudiosos de se considerar tal ciência como uma ciência social e não exata, haja vista a mesma ser classificada como reflexo de cada país e sociedade. Dentre o estabelecimento de normas internacionais, apresenta-se como de extrema importância à conjuntura do ordenamento jurídico, que pode ser considerado como de duas espécies. A primeira é conhecida como direito romano, segundo o qual algo só possui valor a partir de sua menção na lei. Já a partir da segunda espécie, conhecida como direito consuetudinário, a regulamentação está relacionada aos hábitos e costumes da sociedade, sendo este ponto de partida para a regulamentação padrão entre todos os países.

Nesse sentido, o termo aqui mencionado refere-se à primazia da essência econômica sobre a forma jurídica. Tendo em vista o novo cenário contábil, isto é, a inclusão de normas contábeis internacionais, Pedro (2012) chama a atenção acerca da reflexão sobre a primazia da essência sobre a forma, afirmando que a contabilidade somente cumprirá sua real função, isto é, fornecer dados úteis - a partir do momento em que refletir de forma real a realidade econômica e, para tanto, é necessário "observar a primazia da essência econômica sobre a forma jurídica dos eventos econômicos". As consequências desse tipo de mudança de paradigma acabam por afetar profissionais, acadêmicos e outros envolvidos com transações econômicas, que independem do tratamento jurídico. Nesse sentido, o autor em questão trabalha a possibilidade de se repensar as normas contábeis a fim de que a nova maneira implantada seja feita de forma correta.

Segundo COSTA et al (2014), trata-se de um conceito cuja proporção afeta todo o pensamento relacionado à contabilidade até o momento, uma vez que sempre ocorreu o inverso, isto é, a forma sobre a essência. A primeira lei criada com o objetivo de regulamentar a contabilidade, que ocorreu em 1976, já priorizava a forma sobre a essência. Já a lei 11.638/07, já citada anteriormente, tem como prioridade a essência sobre a forma, caracterizada como "a preocupação com a contabilização das diversas operações inerentes a empresa dando ênfase ao objetivo econômico, e não mais a forma com que este objetivo se materializa ou ocorre". Nesse sentido, é válido abordar, como algo auxiliar a compreensão do tema em questão, o conceito de essência e sua relevância para a contabilidade.

De maneira geral, a essência pode ser entendida como responsável por constituir algo, sendo esta a substância ou ideia principal. Já com relação à contabilidade, especificamente, a essência significa aquilo que é exteriorizado pela forma.

De modo geral, os benefícios podem ser resumidos em dois fatores essenciais para o sucesso de qualquer empresa, sendo elas a segurança e a confiabilidade. Ou seja: a obtenção de informações realmente úteis e 
seguras pode beneficiar a empresa trazendo fatores como a garantia de investimentos, melhores condições de planejamento, maior segurança em sua atuação no mercado, entre outros. Para tanto, é necessário o uso de ferramentas e mecanismos que facilitem a obtenção de tais informações. Como exemplo, o chamado "Enterprise Resourcing Planing" (ERP), um sistema que permite à empresa gerar informações seguras com preços não tão altos. Dessa forma, "a informação confiável proporciona a uma organização credibilidade para angariar recursos vindos tanto do sistema financeiro nacional como de investidores em geral no Brasil e fora dele". (PEDRO, 2012, p. 11).

O conceito chave para se compreender essa nova maneira de se trabalhar a contabilidade refere-se à ideia de subjetividade, uma vez que esta "permite a pessoa responsável pelo lançamento dos eventos contábeis julgarem os fatos, através de suposições e conclusões próprias”. (COSTA et al, 2014, p. 3). No entanto, mesmo que a pessoa não esteja preparada para tal responsabilidade em alguns casos, ainda assim é preciso priorizar a realidade no lugar da forma legal, uma vez que esta última pode acabar por ocultar a realidade dos fatos e, dessa forma, distorcer as informações necessárias.

Além disso, os benefícios desse novo foco podem ser vários, sendo os principais relacionados ao fornecimento de informações, isto é: no caso da contabilidade gerencial, por exemplo, não são necessários que se sigam normas fiscais quando se pretende elaborar relatórios, o que permite o oferecimento de informações fiéis e seguras no que se refere ao negócio. Por outro lado, no caso da chamada contabilidade fiscal, esse tipo de aplicação traria consigo possíveis problemas, haja vista os empecilhos encontrados pelo contador no momento em que deseja retratar qualquer fato contábil.

A partir de sua leitura e pesquisa acerca do tema aqui tratado, Cardoso (2012) observa que o ato de se inserir subjetividade nos negócios jurídicos está presente há tempos. Além disso, é observado que o conceito de subjetividade inserido no ramo da contabilidade acaba por aproximar essa área das demais, sendo benéfico nesse sentido.

\section{PROCEDIMENTOS METODOLÓGICOS}

\subsection{DISCUSSÃo}

A natureza desta pesquisa é básica empírica. Quanto aos objetivos, a pesquisa destaca-se pelo viés exploratório e descritivo.

Para analisar o impacto das novas normas de contabilidade adotadas no Brasil a partir de 2008 com a promulgação da lei 11.638/07 e consequente adoção dos padrões internacionais de contabilidade pelas empresas brasileiras, realizou-se uma extensa revisão de literatura para proporcionar fundamentos teóricos. Ademais foi extraído do software Economática ${ }^{\circledR}$, em 09/04/2015, o lucro líquido de empresas que negociam suas ações na BOVESPA e que fazem parte do IBOVESPA.

A fim de buscar um melhor resultado nos testes, foram excluídas da amostra da pesquisa empresas financeiras, pois, por sofreram regulação especial do Banco Central do Brasil, muitas normas ou já eram utilizadas anteriormente à adoção das novas práticas contábeis ou não foram introduzidas de imediato com a promulgação da lei e adoção das IFRS. 
Não obstante, foram excluídas da amostra da pesquisa as empresas que não divulgaram seus resultados por um período de sete anos anteriores ao início da adoção das novas normas e sete anos posteriores a adoção das normas contábeis, sendo excluídas da amostra com o objetivo de não enviesarem os testes estatísticos. Para se eliminar o efeito da inflação nos testes, foi observada no site do Banco Central do Brasil a inflação acumulada e anual dos anos de 2001 até 2014, que correspondem ao período analisado na pesquisa.

A inflação proporcional a cada ano foi descontada do lucro líquido divulgado. Estabeleceu-se tal período de tempo a fim de que houvesse simetria no período de análise, correspondendo sete anos com o padrão contábil anterior e sete anos com efeitos ocasionados pela introdução das novas normas contábeis.

Do total de 64 empresas que fazem parte do referido índice, 34 delas se enquadraram na base de seleção da amostra da pesquisa. As empresas selecionadas respondiam em 09/04/2015 por 44,42 \% de participação no índice IBOVESPA conforme tabela 1.

Tabela 1: Amostra por segmento e participação no índice IBOVESPA.

\begin{tabular}{l|c|c}
\hline \multicolumn{1}{c|}{ Segmento } & Quantidade de empres as & Participação no Índice \% \\
\hline Alimentos e Bebidas & 2 & 11,32 \\
Comércio & 2 & 2,56 \\
Construção & 2 & 0,49 \\
Energia Elétrica & 7 & 4,13 \\
Mineração & 1 & 6,11 \\
Outros & 4 & 5,85 \\
Papel e Celulose & 3 & 2,64 \\
Química & 2 & 3,18 \\
Siderurgica \& Metalurgica & 4 & 2,01 \\
Telecomunicações & 3 & 2,53 \\
Textil & 1 & 0,24 \\
Transporte Serviços & 1 & 1,57 \\
Veiculos e peças & 2 & 1,79 \\
Total & 34 & 44,42 \\
\hline
\end{tabular}

Fonte: elaborada pelos autores, 2015.

A base estatística para realização da pesquisa é o teste de diferença das médias com T de Student, também conhecido como teste de hipóteses, para mensurar se houve mudanças significativas no lucro líquido das empresas de capital aberto.

Um teste tem significância estatística quando é improvável que o resultado encontrado tenha ocorrido por acaso. Para se determinar os limites de diferença aceitáveis, utiliza-se o nível de significância, que é o limite que se tem por base para se afirmar que um desvio é decorrente do acaso ou não. Se os resultados obtidos representarem um efeito real, que não pode ser atribuído ao acaso, com base no nível de significância estabelecido para o teste, pode-se inferir que os resultados são estatisticamente significativos. 
Desse modo, estabeleceu-se para a pesquisa a seguinte hipótese nula $\left(\mathrm{H}_{0}\right)$ e a alternativa $\left(\mathrm{H}_{1}\right)$ :

$\mathrm{H}_{0}$ : Não houve impacto significativo no lucro líquido das empresas de capital aberto após a adoção das normas internacionais de contabilidade.

$\mathrm{H}_{1}$ : Houve impacto significativo no lucro líquido das empresas de capital aberto após a adoção das normas internacionais de contabilidade.

Como o objetivo é verificar se houve mudanças, tanto para um lucro líquido maior ou menor, utilizou-se o teste bicaudal. Foram utilizados dois níveis de significância para o teste, sendo de $5 \%$ e $1 \%$. A fórmula utilizada para obtenção dos resultados é a seguinte:

Onde:

$$
t=\frac{\overline{\mathrm{x}} 1-\overline{\mathrm{x}} 2}{\sqrt{\left(\frac{1}{n 1}+\frac{1}{n 2}\right) s^{2}}}
$$

$\overline{\mathbf{x} 1}$ = Média do grupo Anterior adoção IFRS;

$\overline{\mathbf{x}} 2$ = Média do grupo posterior adoção IFRS;

n1 = Períodos de análise anterior adoção das IFRS;

n2 = Período de análise posterior adoção das IFRS;

A fórmula utilizada para obtenção.

$\mathbf{S}^{2}=$ Variância ponderada das amostras.

Havendo evidências para se rejeitar $\mathrm{H}_{0}$, concluir-se-á que o lucro líquido contábil sofreu mudanças significativas em razão da alteração das normas contábeis. Caso não se rejeite $\mathrm{H}_{0}$, pode-se inferir que o lucro líquido contábil não sofreu alterações relevantes pelo fato das demonstrações contábeis serem elaboradas atendendo aos preceitos da legislação modificada.

\section{ANÁLISE DOS RESULTADOS}

Como já especificado, a base de seleção da amostra da pesquisa foi composta por 64 empresas que compõem o IBOVESPA, sendo que a amostra foi composta de 34 empresas. 
Os resultados encontrados para um nível de significância de 5\% estão demonstrados na tabela 2.

Tabela 2: Resultado para o nível de significância de 5\%

\begin{tabular}{l|c|c|c}
\hline \multicolumn{1}{c|}{ Segmento } & Não rejeita Ho & Rejeita Ho & \% de Rejeição \\
\hline Alimentos e Bebidas & 0 & 2 & 100 \\
Comércio & 0 & 2 & 100 \\
Construção & 1 & 1 & 50 \\
Energia Elétrica & 6 & 1 & 14,29 \\
Mineração & 1 & 0 & 0 \\
Outros & 3 & 1 & 25 \\
Papel e Celulose & 2 & 1 & 33,33 \\
Química & 1 & 1 & 50 \\
Siderurgica \& Metalurgica & 4 & 0 & 0 \\
Telecomunicações & 2 & 1 & 33,33 \\
Textil & 0 & 1 & 100 \\
Transporte Serviços & 0 & 1 & 100 \\
Veiculos e peças & 0 & 2 & 100 \\
Total geral & 20 & 14 & 41,18 \\
\hline
\end{tabular}

Fonte: elaborada pelos autores, 2015.

Os resultados encontrados para um nível de significância de $1 \%$ estão demonstrados na tabela 3 .

Tabela 3: Resultado para o nível de significância de $1 \%$. 


\begin{tabular}{l|c|c|c}
\hline \multicolumn{1}{c|}{ Segmento } & Não rejeita $\mathrm{H}_{0}$ & Rejeita $\mathrm{H}_{0}$ & \% de Rejeição \\
\hline A limentos e Bebidas & 1 & 1 & 50 \\
Comércio & 0 & 2 & 100 \\
Construção & 1 & 1 & 50 \\
Energia Elétrica & 7 & 0 & 0 \\
Mineração & 1 & 0 & 0 \\
Outros & 3 & 1 & 25 \\
Papele Celulose & 2 & 1 & 33,33 \\
Química & 1 & 1 & 50 \\
Siderurgica \& Metalurgica & 4 & 0 & 0 \\
Telecomunicações & 2 & 1 & 33,33 \\
Textil & 0 & 1 & 100 \\
Transporte Serviços & 0 & 1 & 100 \\
Veiculos e peças & 1 & 1 & 50 \\
Total Geral & 23 & 11 & 32 \\
\hline
\end{tabular}

Fonte: elaborada pelos autores, 2015.

Os resultados para um nível de significância de 5\% mostram que 14 das 34 empresas analisadas apresentaram mudanças significativas no lucro líquido após a adoção das IFRS. Essas empresas que apresentaram mudanças significativas possuem 23,99\% de participação no IBOVESPA, o que representa $54 \%$ de participação em termos de representação no índice das empresas analisadas que compõem a amostra da pesquisa.

Não obstante, $83,33 \%$ das empresas que apresentaram mudanças significativas tiveram um aumento do lucro líquido na comparação dos períodos analisados de 2001 a 2007 (anterior a adoção das normas internacionais de contabilidade) e de 2008 a 2014 (posterior a adoção das normas internacionais de contabilidade).

Para um nível de significância de 1\%, 11 das 34 empresas analisadas apresentaram mudanças significativas no lucro líquido após a adoção das IFRS. Tais empresas que apresentaram mudanças significativas possuem $18,74 \%$ de participação no IBOVESPA, o que representa $42,18 \%$ de participação em termos de representação no índice daquelas que compõem a amostra da pesquisa.

Vale ressaltar que $90,91 \%$ das empresas que apresentaram mudanças significativas tiveram um aumento do lucro líquido na comparação dos períodos analisados de 2001 a 2007 (anterior a adoção das normas internacionais de contabilidade) e de 2008 a 2014 (posterior a adoção das normas internacionais de contabilidade).

Para as empresas que apresentaram diferenças significativas nos níveis de significância de $5 \%$ e $1 \%$, a decisão de rejeitar a hipótese nula pode ser interpretada como um indicativo de que a introdução das normas internacionais de contabilidade impactou o lucro líquido das empresas de capital aberto que compõem o IBOVESPA significativamente.

\section{CONCLUSÃO}


O presente estudo teve como objetivo principal analisar os impactos ocorridos no lucro líquido financeiro das empresas de capital aberto listadas na BMF\&BOVESPA que compõem o IBOVESPA após promulgação da lei 11.638/07 e adoção das normas internacionais de contabilidade.

A introdução das normas internacionais de contabilidade no Brasil a partir de 2008 trouxe novos conceitos e uma nova abordagem para a contabilidade no Brasil. Por meio da revisão da literatura e pesquisas realizadas, foram evidenciadas as principais alterações trazidas pela nova legislação, destacando-se como fatores principais as alterações das práticas contábeis que foram adotadas no Brasil através do marco regulatório da contabilidade financeira criada para convergir os padrões contábeis locais para internacionais, atribuindo-se como consequências uma série de modificações na legislação.

A expectativa da convergência com o IFRS era de que, como ocorreu em outros países, no Brasil, as empresas adquirissem benefícios de liquidez, menores custos de capital e maior valorização e atratividade no mercado, levando em consideração a importância da internacionalização e suas normas.

A essência sobre a forma apresenta-se como de extrema importância à conjuntura do ordenamento jurídico. Tendo em vista o novo cenário contábil, isto é, a primazia da essência sobre a forma, fornecendo dados úteis a partir do momento em que refletir de forma real a realidade econômica, observando a primazia da essência econômica sobre a forma jurídica dos eventos econômicos.

Não obstante, a pesquisa analisou de forma estatística se houve mudanças significativas no lucro líquido das empresas não financeiras que compõem o IBOVESPA.

As evidências empíricas apontam que houve diferenças significativas para essas empresas a um nível de significância de $5 \%$ e 1\%. Embora as diferenças significativas não tenham ocorrido para todas as empresas, $41 \%$ das empresas analisadas mostraram diferenças significativas a um nível de significância de $5 \%$.

Do total de 14 empresas analisadas, 12 apresentaram um aumento do Lucro Líquido e 2 apresentaram uma diminuição do Lucro Líquido. Para um nível de significância de 1\%, 32\% dessas empresas apresentaram diferenças significativas, sendo que 10 das 11 empresas analisadas apresentaram um aumento do Lucro Líquido e 1 apresentou uma diminuição do lucro líquido após a introdução das normas internacionais de contabilidade.

Após a revisão da literatura e análise dos resultados apresentados, foram reunidas evidências e informações para desenvolver uma resposta coerente ao questionamento que moveu esta pesquisa, isto é, acerca da possibilidade de a alteração das práticas contábeis impactarem o lucro líquido das empresas de capital aberto listadas na BM\&F Bovespa que compõem o Ibovespa.

Concluiu-se, com base nos testes realizados, que houve uma alteração significativa no lucro líquido das empresas de capital aberto que compõem o Ibovespa, para o período analisado de 2008 a 2014 em comparação com o período de 2001 a 2007, de acordo com a metodologia aplicada para realização da pesquisa, evidenciando um aumento no lucro líquido após a adoção das normas internacionais de contabilidade, ressaltando que essa diferença significativa não se estendeu a todas as empresas.

Embora os resultados encontrados não estejam em consonância com as pesquisas realizadas por Braga et 
al. (2011), que defendem que não há diferenças significativas nos indicadores de rentabilidade, vale ressaltar que a diferença em indicadores financeiros relativos a rentabilidade pode estar relacionada ao aumento ou diminuição do lucro, bem como ao aumento ou diminuição de outras variáveis que os compõem, pois os mesmos analisam o conjunto sem explicar qual o fator que impactou na alteração do indicador financeiro analisado.

Ademais, como limitação da pesquisa, não foi levada em consideração outras varáveis que podem afetar o lucro líquido como a taxa de juros da economia, taxa de reinvestimento entre outros.

Desse modo, sugere-se para novas pesquisas que sejam analisadas diferenças significativas nas outras variáveis que compõem os indicadores financeiros relativos a rentabilidade após a adoção das IFRS.

\section{REFERÊNCIAS}

BAPTISTA, E. M. B. Ganhos em Transparência Versus Novos Instrumentos de Manipulação: o Paradoxo das Modificações Trazidas Pela Lei N 11.638. RAE-Revista de Administração de Empresas, v. 49, n. 2, abr-jun, 2009.

BRAGA, J. P.; ARAUJO, M. B. V. de; MACEDO, M. A. da S.; CORRAR, L. J Análise do impacto das mudanças nas normas contábeis brasileiras: um estudo comparativo dos indicadores econômicofinanceiros de companhias brasileiras para o ano de 2007. Revista Contemporânea de Contabilidade, Florianópolis, v. 8, n. 15, p. 105-128, 2011.

BRASIL. Instrução normativa $\mathbf{n}^{0}$ 1.492, de 17 de setembro de 2014. Disponível em <http://www.receita.fazenda.gov.br/ Legislacao/ Ins/2014/in14922014.htm>. Acesso em 14/11/2014.

BOVESPA. bmf. Como e por que tornar-se uma companhia aberta. Disponívelem<http://www.bmfbovespa.com.br/pdf/guiaaber.pdf>. Acesso em 08/03/2014

CARDOSO, Glaydson Ferreira. O direito tributário e as normas internacionais de contabilidade: uma análise de sua recepção e reflexos no ordenamento jurídico brasileiro. Nova Lima - MG: Faculdade de Direito de Milton Campos, 2012.

COSTA, Vanessa Matos; LORENZETT, Daniel Benitti; FRANCESCHI, Franciéli Rosa; PEGORARO, Delvan Guerreiro; ROSSATO, Marivane Vestena. Contabilidade: A essência sobre a forma. [Online]. Acesso em $01 / 12 / 2014$. Disponível <http://www.unifra.br/eventos/sepe2010/2010/Trabalhos/sociais_Aplicadas/Completo/4642.pdf>

LODDI, Cesar. As principais mudanças da Lei 11.638/07 e as normas internacionais de contabilidade - Um estudo de caso em uma sociedade anônima. [Online]. Disponível em <http://cesarloddi.com.br/educacional/wpcontent/uploads/2014/02/Mudan\%C3\%A7as_Lei_11638.pdf>. Acesso em 14/11/14.

MARTINS, Eliseu; SANTOS, Ariovaldo dos. Alguns pontos da Lei 11.638 e a internacionalização da contabilidade brasileira. Ibef News, São Paulo, p.28-30, mar. 2008. 
NOGUEIRA JUNIOR, Edgard et al. Início da adoção das IFRS no Brasil: Os impactos provocados na relação entre o lucro e o fluxo de caixa operacional. Contabilidade Vista \& Revista, v. 23, n. 1, p. 47-74, 2013.

PEDRO, Ismael Sanches. A aplicabilidade das novas normas brasileiras de contabilidade (IFRS) nas pequenas e médias empresas, seus benefícios e os conflitos com o sistema tributário nacional. Barretos-SP, UNPR: 2012.

SANTOS, E. S.; CALIXTO, L. Impactos do Início da Harmonização Contábil Internacional (lei 11.638/07) nos Resultados das Empresas Abertas. RAE - eletrônica, v. 9, n. 1, janeiro-junho, 2010.

SANTOS, Luis Paulo Guimarães; LIMA, Gerlando Augusto Sampaio Franco; FREITAS, Sheizi Calheira; LIMA, Iran Siqueira. Efeito da Lei 11.638/07 sobre o conservadorismo condicional das empresas listadas BM\&FBOVESPA. R. Cont. Fin. - USP, São Paulo, v. 22, n. 56, p. 174-188, maio/jun./jul./ag

[1] Contador, Pós graduando em contabilidade pública e responsabilidade fiscal, contador da faculdade de direito de São Bernardo do Campo.

[2] Contador, mestrando em contabilidade.

[3] Contador, Auditor da KPMG.

\section{PUBLIQUE SEU ARTIGO CIENTÍFICO EM:}

https://www.nucleodoconhecimento.com.br/enviar-artigo-cientifico-para-submissao 